\title{
PSYCHOLINGUISTICS IS DEFINITELY TIED UP TO PROSODY
}

\section{LOURENÇO-GOMES, Maria do Carmo ${ }^{1}$}

${ }^{1}$ Centro de Estudos Humanísticos da Universidade do Minho

\begin{abstract}
For almost two decades, phonologists, phoneticians and psycholinguists have devoted attention to the value of prosodic information during silent reading. Until then information on the influence of syntactic and semantic aspects in silent reading was the focus of attention in Psycholinguistics. Despite the joint efforts of researchers, there are many issues to be explored regarding two main domains. The first relates to individual prosodic parameters to languages that can have influence on the processing of sentences. The second refers to how the parser uses the prosodic information present in written stimulus on the understanding of silently reading. In both situations, it will be necessary to focus on methodological aspects in addition to theoretical ones. If on the one hand we already have strong evidence about the influence of prosody in silent reading, on the other hand it cannot be denied that measuring the prosody mentally organized by the reader during reading process is not an easy task. Thus, this article intends to emphasize the complexity concerning the theme and at the same time the needs for further investigation in each language alone. It presents some insights from the early researches in Portuguese language and offers some suggestions for future investigation.
\end{abstract}

Keywords: sentence processing; syntax-prosody interface; implicit prosody; reading; Psycholinguistics

\section{Introduction}

Many syntactically ambiguous sentences are uttered in prosodically different manners in order to undo the ambiguity. For many decades they have been of great interest among a huge amount of investigations, and they have shown that speakers/listeners share knowledge about the prosodic information present in the speech signal, and that they use this information as cues to ascribe a given interpretation to the syntactic structure. They have also established that the cues which set prosodic boundaries are potentially relevant to the interpretation of utterances which have a certain kind of syntactic ambiguity (e.g., Lehiste, 1973; Beach 1991; Price et al., 1991; Shattuck-Hufnagel \& Turk, 1996), and that other cues related to rhythm and intonation are also important to the organization of the sentence constituents' prosodic phrasing. These topics of inquiry, usually circumscribed to the Phonetics and Prosodic Phonology areas, have been incorporated into investigations of Psycholinguistics (Schafer, 1997; Fodor, 1998; Schafer et al., 2000; Carlson, Clifton Jr \& Frazier; 2001, among many others).

The experimental apparatus and the investigation techniques employed in the examination of language processing have been highly refined in the last decades. However, there remain many doubtful points in the studies of the syntax-prosody interface and in its implications on sentence processing (cf. Breen, 2014). As languages differ in many aspects of their prosodic organization, data about oral production and perception are still scarce to cope with so many questions that arise in the Psycholinguistic field. It is still necessary to determine and to characterize prosodic patterns that occur in particular languages more clearly, and to establish the existing differences among the patterns of dissimilar languages. In the overall frame of sentence processing, Fodor (1998) and Bader (1998) have suggested that some matters of syntactic parsing throughout languages could be attributed to differences in the prosodic components of their grammars. Lovrič (2003) draws attention to a crucial question: what prosodic differences are relevant? To some extent, Fodor has stimulated many of the studies on the influence of prosodic aspects during sentence processing (cf. Frazier \& Gibson, 2015).

These studies have demonstrated that, during phonological coding in oral and silent reading, some prosodic information not always represented graphically, is mentally projected on 
written stimulus, which, regarding silent reading, has become known as "implicit prosody" or "silent prosody" among psycholinguists (e.g., Fodor, 2002a,b; Lovrič, 2003; Jun, 2003, 2010; Augurzky, 2005; Traxler, 2009; Bishop, Chong \& Jun, 2015). In Portuguese language, a research team, especially from Universidade Federal do Rio de Janeiro, have exhaustively dedicated their attention and interest to the subject in a number of off-line and on-line studies (Lourenço-Gomes, 2002, 2003; Finger \& Zimmer, 2002; Maia et al, 2004; Lourenço-Gomes, Maia \& Moraes, 2005; Lourenço-Gomes \& Moraes, 2005; Magalhães \& Maia, 2006; LourençoGomes \& Maia, 2007; Maia \& Finger 2007; Lourenço-Gomes, 2008; Maia et al 2007; Lourenço-Gomes \& Lindemann, 2012), and have been followed by other researchers (e.g., Fonseca, 2012; Magalhães \& Fonseca, 2014). In Psycholinguistics cannot escape prosody, Fodor (2002a) proposes the "Implicit Prosody Hypothesis" (IPH), p. 2:

In silent reading, a default prosodic contour is projected onto the stimulus, and it may influence syntactic ambiguity resolution. Other things being equal, the parser favors the syntactic analysis associated with the most natural (default) prosodic contour for the construction.

In Fodor (2002b) she suggests a systematization of studies on IPH from a few seemingly simple steps (p. 4):

To test the IPH:

[1] Find a factor $F$ which can be manipulated in an experiment, and which measurably affects the OVERT prosody of a sentence.

[2] Show that the overt prosodic difference caused by F measurably influences an ambiguity resolution preference in parsing.

[3] Show (or claim?) that F does not affect parsing DIRECTLY.

[4] Include F in a silent reading task. Is ambiguity resolution affected by F as it is the listening task?

The studies that were influenced directly or indirectly by Fodor at that time (e.g., Quinn et al, 2001; Jun, 2003; Lovrić, 2003; Lourenço-Gomes, 2003; Augurzky, 2005) confirmed that the four steps were in fact not simple at all (cf. Breen, 2014, for a review on implicit prosody). In the following section, some fundaments in the area of Psycholinguistics that directed the attention of researchers for the importance of prosody in the processing of sentences during silent reading are presented. Although this background in the literature has been repeatedly reported, it demonstrates some reasons for the concern about the prosody in the sentence processing presented in the following section on the first studies with data from the Portuguese language.

\section{The insight into implicit prosody in Psycholinguistics}

Slowiaczek \& Clifton Jr. (1980) have provided strong indications of the value of prosody in silent reading. In one of their experiments, the authors presented short stories to be read to a group of participants and to be heard with headphones to a second group. In half of the stimuli the subjects were asked to read / listen to the stories in silence, who, therefore, would be free to subvocalize. In the other half, subjects were asked to count from one to ten repeatedly while reading / listening to the stories so that subvocalization was necessarily suppressed. After the presentation of each stimulus the subjects were free to subvocalize and a test sentence was visually or audibly presented, depending on the experimental condition. Then, the participants 
had to judge whether the test sentence was compatible or not with the story they had just $\mathrm{read} /$ heard. The results showed that when the subvocalization was suppressed, the error rates were higher in the reading condition than in the hearing condition, which led the authors to conclude that suppression of subvocalization interferes in some process specifically necessary to the reading skills. The results of a second experiment have showed that subvocalization helps readers to combine distinct pieces of information and, thus, provide better understanding of the text read. In the readers whose subvocalization was suppressed the elaboration of inferences was more difficult.

Besides the old interest on subvocalization effects in different domains of research (e.g., Buswell, 1947), namely on its role in memory mechanism (e.g., Locke \& Fehr, 1972; Standing et al, 1980; Standing \& Curtis, 1989, among others), studies on prosody in sentence processing have explored oral production and perception modalities in a series of studies, and it has begun well before "implicit prosody" was so called in Psycholinguistics (e.g., Lehiste, 1973; Warren, 1985; Price, Ostendorf, Shattuck-Hufnagel \& Fong, 1991). The interest of Psycholinguistics in the studies made about the syntax-prosody interface, and more specifically in the experimental investigation of the manifestation of prosodic information on sentence processing, has been made evident in a number of studies (Beach, 1991; Price et al., 1991; Nagel et al., 1996; Schafer, 1997; Kjelgaard \& Speer, 1999; Carlson, Clifton \& Frazier, 2001; among others).

Fernández \& Sekerina (2015) have recently presented new data on the relative clause attachment preference to complex NPs (see (1) below) by presenting subjects with spoken sentences describing geometric forms in order to minimize semantic and pragmatic effects on the interpretation of ambiguity (e.g., Here is a pink triangle and a yellow triangle. They have different color tips. What color is the tip $p_{\mathrm{N} 1}$ of $f_{\mathrm{P}}$ the triangle ${ }_{\mathrm{N} 2}\left[_{\mathrm{RC}}\right.$ that has a umbrella in the midle]?). Sentences were presented to participants with one of two prosodic contours: compatible with high attachment (phrasal break after NP2) or compatible with low attachment (phrasal break after NP1). The task of the subjects was to choose between three visual depictions of the sentences (low attachment, high attachment, ambiguous) that they considered corresponding to the phrase heard. In addition, measures of eye movements were extracted. The results were consistent with previous studies in English (low attachment preference), which suggest that overt prosody may facilitate the processing of the examined structure.

Bishop, Chong \& Jun (2015) investigated individual differences in English speakers in a listening experiment using ambiguous relative clauses (NP1-P-NP2-OR) which were manipulated in three ways: depending on the placement of prosodic boundaries (after NP1or after NP2) and with no boundary. The sentences should be best fit with one of two visual scenes corresponding to the two interpretations that undo the ambiguity (high attachment or low attachment). After this task the participants were asked to complete a self-report questionnaire measuring autistic-like personality traits in the non-clinical population (AQ-Autism-spectrum quotient. See Baron-Cohen et al, 2001). The authors intended to explore the subjects' sensitivity to the location of prosodic boundaries, the effect of manipulating these boundaries in the interpretation of the examined ambiguity, as well as the relationship of such effects and autistic traits. With regard to the latter, the results were only marginally significant (but see Jun \& Bishop, 2015). Among many interesting findings, however, they suggest that there may be multiple prosodic strategies used during the processing of ambiguous sentences and that individuals may differ slightly in their sensitivity to different prosodic cues related to prominence. However, most of the investigations prior to the end of the 80's and the beginning of the 90's have been not much concentrated on the information present in the speech sign (in the phonological component of grammar), paying more attention to the syntactic and semantic processing. 
Some of the reasons of the growing interest about the prosody-syntax-processing relationship may be due to the development of theoretical propositions of a phonology-syntax interface, the improvements in the area of acoustic and instrumental phonetics and the theoretical deepening of parser models. However, the emergence of a great interest in the literature for the "implicit prosody" is considered to have been triggered by an issue thoroughly discussed in the sentence processing field: the universality of sentence parsing connected to the problem of relative clauses with complex NPs. In the late 1970s Frazier and Fodor (Frazier \& Fodor, 1978; Frazier, 1979) suggested a model of parser influenced under many aspects by Kimball's assumptions concerning sentence processing (Kimball, 1973) and by Fodor, Bever \& Garret (1974) propositions. Kimball (1973) has proposed a parser that builds the surface structure based on a set of interconnected principles surveyed in the English language, and suggested an extension of his model to other languages. Frazier \& Fodor (1978) maintain a universal parser outlook, but suggest changes in Kimball's proposal. The principles are simplified down to a basic formulation that forbids postulating potentially unnecessary nodes (Minimal Attachment). Frazier (1979) includes the Late Closure principle to the model (as soon as possible the constituents are attached to the lowest node in construction). The two Principles were considered basic strategies deployed in the parser's operational routines. The model has provided a fast and efficient parser in which initial decisions are based solely on structural information, regardless of whether these decisions are subsequently incorrect, that is, even if the "packing" in the first stage takes the parser to a temporary error, a garden path in Frazier's terminology (1979, p.76). Frazier and Fodor's proposal has been discussed in a wide range of studies and is now known as Garden Path Theory. Their initial model had been scrutinized in different studies (e.g., Frazier, Clifton Jr. \& Randall, 1983; Frazier \& Rayner, 1982, 1987) although only substantially amended in the Construal model (Frazier \& Clifton Jr., 1996). The NP1-P-NP2-RC structure, as in (1), is analyzed based on the Late Closure principle.

(1) A man recognized the accomplice ${ }_{\mathrm{NP} 1}$ of $f_{\mathrm{P}}$ the thief $\mathrm{NP}_{\mathrm{NP}}$ [RCthat escaped after the robbery].

In the face of an ambiguity as in (2), the RC would be preferentially attached to NP2 (the thief). Cuetos \& Mitchell (1988), however, raised serious doubts about the proposal of a universal parser, presenting data which indicated that the late closure principle did not hold in Spanish. In this language, data pointed to a preference towards another strategy (early closure): the RC attachment to NP1 (the accomplice) rather than to NP2 (the thief). By this time, other proposals on the operating parser began to emerge.

Cuetos, Mitchell and colleagues (e.g., Mitchell \& Cuetos, 1991, Cuetos, Mitchell \& Corley, 1996; Brysbaert \& Mitchell, among others) have suggested that the parser routines are adjusted to the input of the environment rather than limited by specific parameters as initially suggested in Cuetos \& Mitchell (1988). The basic idea of their premise is that ambiguities are initially resolved according to statistical prevalence of alternative reading patterns in the language. In other words, if in a language high attachments (NP1) in unambiguous material are more frequent than low attachments (NP2), then in this language there would be a greater tendency for high attachments (Cuetos, Mitchell \& Corley, 1996. See also Mitchell et al, 1995 for details about other exposure-based models). Gibson et al (1996) proposed that parser operations would be essentially guided by two factors which competitively interact: (i) Recency Preference Preferentially ("attach structures for incoming lexical items to structures built more recently.", p. 41), which correspond to the basic formulation of Frazier and Fodor's late closure principle, and (ii) Predicate Proximity ("Attach as close as possible to the head of a predicate phrase.", p. 41). The former is assumed to be universal in the sense that it meets the constraints imposed by the working memory, while the latter is subject to the parametric variations of the language. Hemforth and colleagues (e.g., Hemforth et al, 1999; Hemforth \& Konieczny, 2002) consider that syntactic and anaphoric binding are competitive in computing the sentence: when 
an attachment decision has to be made, the syntactic factors fulfill limitations of working memory and anaphoric binding relates to parametric variations of the language.

In the Construal model Frazier \& Clifton Jr. (1996) suggest that the general principles (Minimal Attachment and Late Closure) proposed by Frazier and Fodor do not apply equally to all structures. Obligatory constituents, as complements, have essential properties that need to be quickly incorporated into the previous material in the phrase marker and thus follow the universal principles of attachment. Non-obligatory constituents, as adjuncts, are associated (rather than attached) to the current thematic processing domain and are thus interpreted on the basis of whatever information is available (semantic, pragmatic, etc.). The NP1-P-NP2-RC structures are therefore not subject to the Late Closure principle. Instead of "attached" they are "associated" with the current thematic processing domain.

Fodor (1998) offered an alternative proposition to explain the differences found among languages in the interpretation of the NP1-P-N2-RC structure seen in (1). Keeping in sight a universal parser the author ponders about the fact that the differences are due to the prosodic structure, which is different among the different languages, and not in the universal principles of the parser. To put it in a simple way, it is grounded on the assumption that both the syntactic structure and the prosodic structure are computed by the parser in the initial stage of sentence processing. Resuming some basic ideas of the model presented in Frazier \& Fodor (1978), she suggests that a "prosodic processor" builds phonological phrases based on syntactic and lexical information of a lower level, and also based on prosodic cues that happen to be had by the input. Thus, for instance, the prosodic phrasing that it imposes would influence the syntactic parser's higher level decisions. Fodor goes further to suggest that this influence also occurs in silent reading. Such an assumption was formalized by Fodor (2002a) in the Implicit Prosody Hypothesis (IPH), as seen above.

In short, different proposals have been advanced to explain these differences, and they fall into two main categories: those that maintain the outlook of a universal parser whose operations are internally determined, and those that consider that the parser's operational routines are essentially guided by parametric properties of grammar (cf. Fernández, 2003 for a review). The relevant question for later studies was then "What is the reason for the differences found among languages?". This question challenged the field at that time when the understanding about the nature of the human sentence processing mechanism was only at the beginning. In an effort to explain the reason for differences between languages in attachment preference, the relative clause case has been examined in a huge number of studies and it is currently still under study (e.g., Traxler, 2007; Grillo \& Costa, 2014; Fernández \& Sekerina, 2015; Grillo et al, 2015; Jun \& Bishop, 2015; Hemforth et al, 2015).

Considering this has been a serious concern among a number of studies on the RC attachment subject, the summary above is intended to highlight the fact that "the problem of relative clause attachment" plays an important role in motivating the different proposals that came up following the Frazier and Fodor's parsing model. All proposals seemed to present the underlying idea of the solution for such problem.

The problem of relative clause attachment seems not to have been effectively solved with the suggestion of Fodor (1998, 2002a). However, the prosodic proposal has undoubtedly brought new issues to the area of sentence processing (cf. Frazier \& Gibson, 2015). Just to begin with, a new challenge has been proposed to researchers: How to measure the effects of mentally represented prosodic phrasing during silent reading?

\section{The insight into implicit prosody in Portuguese}

By the time Fodor stressed the needs for incorporating prosody into sentence processing researches, a few works investigating the subject were in progress or just finalized, most motivated by her. According to Lovrić (2003), the following languages had been examined right after the Fodor's prosodic assumption: Japanese (Kamide et al, 1998), German (Walter et al, 1999), English (Fernández \& Bradley, 1999), French (Pynte \& Colonna, 2000), Croatian (Lovrić, 2003), Dutch (Wijnen, 2001), Spanish (Fernández, 2003), Brazilian Portuguese 
(Lourenço-Gomes, 2002). Therefore, one of the main concerns of the researchers at that time was how to measure the prosody that the readers project mentally on written stimulus during the silent reading.

Lourenço-Gomes (2003) has examined Fodor's assumption $(1998,2002 \mathrm{a})$ that in the languages in which the most natural phrasing, as the structure in (1) above, favors the presence of a prosodic boundary to the left of the RC, readers prefer to attach the RC to NP1. And in the languages in which a boundary at this place is not demanded, the preference would be for an attachment to NP2 (high and low attachment, respectively). She has used the length of the RC as a means of modifying the prosodic phrasing pattern and examining the correlation between the differences observed and the attachment preferences of the RC. The assumption was that when the $\mathrm{RC}$ was long (two or more words after the relative pronoun) its propensity to present a boundary to its left, building up an independent prosodic constituent, would be bigger than when it was short (just a word after the relative pronoun). This way readers would manifest a bigger preference for high attachment in the long RCs than in the short RCs (see Chart 1), in accordance to the proposition of the IPH.

Table 1. Expected prosodic-syntactic alignments and respective attachment preferences, according to the IPH

\begin{tabular}{|c|c|c|}
\hline TYPE & LONG RC & SHORT RC \\
\hline $\begin{array}{c}\text { Prosodic-syntactic } \\
\text { alignment }\end{array}$ & $\ldots$ [NP1 of N2][RC] & $\ldots[$ NP1 of N2 \\
\hline $\begin{array}{c}\text { Preference of RC } \\
\text { attachment in a silent } \\
\text { reading task }\end{array}$ & HIGH & $\begin{array}{c}\text { NEUTER } \\
\text { or LOW }\end{array}$ \\
\hline
\end{tabular}

The choice of the length feature and this latter assumption were based on the propositions on the relationship between the prosodic and syntactic structures. They introduce evidence that the length of the constituent affects the prosodic phrasing, especially in the domain of the Intonational Phrase (IP), which is a higher level domain in the prosodic hierarchy, and that permits a wide restructuring variability. Besides this variability, it is considered that there having no syntactic constraints or impositions related to speech speed and style or prominence, a single IP can be divided in others of lesser proportions, although there is an inclination to avoid series of intonational phrases that are too little or that have very different lengths (Nespor \& Vogel, 1986, p. 194). Length of constituent constraints and syntactic-prosodic alignment proposed in other studies (e.g. Selkirk, 2000; Sandalo \& Truckenbrodt, 2002) were also considered.

In the study, acoustically analyzed oral production data suggested that a boundary to the left of long RCs was more frequent than a boundary to the left of short RCs, and interpretation data of the silent reading sentences suggested a preference for high attachments in the long RCs and for low attachment in the short RCs. All results were statistically reliable. The study showed evidence that the prosodic phrasing patterns in oral production could predict attachment preferences to silent reading in the structure under scrutiny, supporting the IPH (see also Lourenço-Gomes, Maia \& Moraes, 2005, for more details).

In Lourenço-Gomes (2003), although the correlation of data from oral production and silent reading has supported the IPH in a significant way, in the oral production data the 
duration of the tonic syllable was the parameter that most constantly correlated with the examined boundary. So, the point was whether the greater duration observed in the N2 tonic syllable at the long RCs rather than at the short RCs could be by itself a relevant parameter to the perception of a prosodic boundary.

Given the diversity of information attributed to prosody, it is mandatory to establish what kind of information is at hand when the speakers have to solve an ambiguity using this information. In terms of analysis and description, prosody is dealt with under different views in the literature, one which is more phonetic and another which is more phonological. In the first view, physical-acoustic indices that describe suprasegmental phenomena are measured and manipulated, as well as their relationships with speech's segmental units, thus establishing correlations between speech and its perception. In the second, more abstract view, we concern ourselves with the organization and mental representations of prosodic phrasing, intonation, and the rhythm structures of the languages. These two domains, so to speak, may be considered the "two sides of the same coin: although phonologists give primacy to an abstract description of the phenomena concerned, they look for empirical evidence in the realm of speech" (Nooteboom, 2010, p. 231).

The parser seems to be responsive to information of certain levels of prosodic phrasing during processing. On phonological grounds, the most natural choices seem to be the level of the phonological phrase (PP) and the level of the IP. The PP uses more general syntactic notions than the lower levels, making predictions for other languages as well as being the application domain of several phonological rules in a number of languages. Although the IP is influenced by syntactic factors, it presents much flexibility to its own formation and to the rules of restructuring, as semantic factors related to the relative prominence of their constituents and performance factors related to the speed and style of speech (Nespor \& Vogel, 1986).

On the other side of the coin view, further phonetics studies on speech production and perception usually indicate that different acoustic cues such as lengthening of the end of the word, fundamental frequency (F0) modulation, word duration and pauses are important boundary indicators (Streeter, 1978; Lehiste, 1983; Umeda, 1982).

Going back to the question above: would duration be by itself a relevant parameter to the perception of a prosodic boundary? Lourenço-Gomes \& Moraes $(2005)^{*}$ investigated the effects of the variation of vowel duration on the perception of the prosodic break in Brazilian Portuguese. The basic structure was a syntactically ambiguous sentence in which a relative clause (RC) can modify one of the complex NP nouns (NP1 or NP2) that appear in the main clause, as in (1):

(1) A música alta incomodava o amigo $\mathrm{NP}_{\mathrm{NP}} \mathrm{do}_{\mathrm{P}}$ menino $_{\mathrm{NP2}}$ [RCque comia na lanchonete da esquina].

(The loud music was bothering the friend of the boy that was eating at the coffee-house.)

The sentence was read aloud by a linguist, from a taperecorder, who was instructed to read it in the most neuter way possible, at a natural speed and avoiding inserting a pause before reading the RC. This sentence was synthesized by speech synthesis software (CSL-ASL) and it served as a basis for the creation of stimuli to be presented to the listeners. In these stimuli the durations of the stressed and post-stressed vowels of the word that preceded the RC (preboundary word) were, in isolation and in combination, progressively lengthened and shortened

\footnotetext{
* At this point a thank to Professor João Moraes is deserved. The oral production data pointed out in Lourenço-Gomes, 2003 have motivated the development of a series of laboratory experiments that tried to explain mainly the primacy of duration over F0 in the production of the prosodic breaks in their study, in which the author and her co-advisor, João Moraes, have spent a lot of time.
} 
at percent intervals, being the F0 and intensity kept unchanged. Two different versions with random distribution of stimuli were presented to two different groups of subjects (forty in all). In a forced choice task, the subjects, unaware of the purposes of the study, were asked to indicate the presence/absence of a boundary between the RC and the immediately preceding word. Data especially suggested that in BP the lengthening of the tonic vowel is, in isolation, perceived as a sign of prosodic boundary by the listeners. Comparatively to the tonic vowel, the data suggested that the lengthening of the post-tonic vowel of the same word has a less relevant role in the boundary perception at that place.

To determine the stimuli that would be presented to the listeners their unaffectedness was especially taken into account through a previous assessment made by the five moderators, including the two researchers. Any manipulations that caused interferences and were considered inadequate as to the unaffectedness of the stimuli were discarded. Examples of manipulations that negatively alter the unaffectedness stimuli: Increases greater than $80 \%$ overexposed vowel duration. It was not advisable that a timely perception of the prosodic boundary could be overruled by a clear perception of vowel. When the tonic vowel duration was excessively diminished (more than 60\%), a click was heard.

Beyond the stimuli unaffectedness it was considered that intervals under $20 \%$ in the duration of the variation were perceptually irrelevant to this investigation. The listeners' selection of the implemented duration differences was not significant.

Their hypothesis was that in BP the individual lengthening of the tonic vowel, more than the word ending lengthening, could be taken by listeners as a cue of prosodic boundary. Thus, for analytical purposes they took as critical the lengthening rather than the shortening of tonic or post-tonic vowels duration of the manipulated word, as to the base sentence. Two main aims as to the shortening of the manipulated unities: (i) to establish a line of support that allowed showing the base sentence did not present a break at the scrutinized place that could be relevant in a perceptual point of view, and (ii) to provide support, so that listeners could establish the boundary presence-absence contrast.

Table 2. Frequency of positive answers showing prosodic break perception to the left of the $\mathrm{RC}$ according to variations in the duration of stressed or post-stressed vowels of the immediately previous word (menino - boy). $\mathrm{N}=\mathbf{4 0}$

\begin{tabular}{|c|c|c|c|c|c|c|c|c|c|}
\hline \multirow{2}{*}{$\begin{array}{c}\text { VARIATION OF VOWEL } \\
\text { DURATION }\end{array}$} & \multicolumn{3}{|c|}{$\begin{array}{c}\text { \% LENGTHENING FROM } \\
\text { BASE-SENTENCE }\end{array}$} & \multicolumn{5}{c|}{ \% SHORTENING FROM BASE- } \\
\cline { 2 - 10 } & 20 & 40 & 60 & 80 & -20 & -40 & -60 & -80 & -99 \\
\hline $\begin{array}{c}\text { stressed vowel } \\
\text { (menIno) }\end{array}$ & 60.0 & 67.5 & 95.0 & 97.5 & 7.5 & 10.0 & 5.0 & --- & --- \\
\hline $\begin{array}{c}\text { post-stressed vowel } \\
\text { (meninO) }\end{array}$ & 30.0 & 47.5 & 30.0 & 25.0 & & & 15.0 & 12.5 & 17.5 \\
\hline
\end{tabular}

Lourenço-Gomes \& Moraes's survey (2005)

Data especially suggested that the presence of a prosodic break was perceived more frequently when there were increases in the duration of the stressed vowel than when increases occurred in the vowel of the post-stressed syllable. The "next question" of the authors remains important: What are the effects of these variations on the syntactic ambiguity resolution in silent reading? This issue needs further investigation.

A more abstract aspect in terms of measurement drew researchers' attention to the prosodic influence in reading: the artificial segmentation of sentences in a technique widely 
used in psycholinguistics: the self-paced reading technique (Gilboy \& Sopena, 1996; Traxler, 2009).

Lourenço-Gomes (2008) examined sentence segmentation effects involving restrictive relative clauses in which two nouns of a complex noun phrase are candidates to attachment of the relative clause (RC) in the structure NP1-P-NP2-RC. The study involved four psycholinguistic experiments, three self-paced reading and one self-paced listening, which manipulated the type of sentence segmentation and the type of forced attachment, through number agreement (plural/singular) and gender agreement (female/male). The kind of segmentation took into account two break sites (between NP1 and NP2, conditions of high boundary; or between NP2 and the RC, conditions of low boundary). Expected differences in the reading times (on-line measurement) of the segment that undid ambiguity were: more local acceptance was expected than non-local to the RC attachment in the conditions where a break was imposed between NP1 and NP2; and, by contrast, it was expected greater non-local acceptance than local in those where a break was imposed between NP2 and the RC. The reason is based on the phrasing pattern imposed by the type of segmentation: in sentences with a high boundary, there being no discontinuity between the local host and the $\mathrm{RC}$, the phrasing supposedly projected over the written input would force local attachment, and in sentences with a low boundary, the separation of the RC as an independent unit would leave it freer to attach itself to the non-local host. Answers to comprehension questions were also analyzed. Quantitative and qualitative data of the on-line and off-line measures especially revealed that findings can adjust themselves to the assumption that artificially imposed segmentations over the written input cause some impact over the processing. Additionally, differences were observed when sentence ambiguity was undone by number and gender agreement.

Lourenço-Gomes, Costa \& Maia (2011) used the NP1-P-NP2-RC structure to examine more specifically the integration of gender and number cues in European Portuguese (EP), and to evaluate influences of this type of morphological information in the comprehension of the sentences. In two self-paced reading experiments, the sentences were presented word by word on a computer screen, each followed by two alternatives that verified the understanding of the RC attachment to NP1 or to NP2. The items were manipulated as to undo the ambiguity in a full paradigm of number and gender agreement, then forcing the RC attachment in favor of NP1 or NP2, as exemplified in (2a,b):

(2) a. O detective procurou o vizinho $o_{[ \pm s i n g]}$ do criado $_{[ \pm \operatorname{sing}]}$ que estava $a_{[ \pm \operatorname{sing}]}$ implicado $_{[ \pm \operatorname{sing}]} \mathrm{em}$ vários casos.

b.O detective procurou o vizinho $[ \pm$ masc $]$ do criado[ \pm masc $]$ que estava implicado[ \pm masc $]$ em vários casos.

(The detective searched for the neighbor of the servant who was involved in many cases)

The grammatical strategies of disambiguation of number and gender in EP, commonly employed in other languages throughout the investigation of this structure, reveal significant differences as to the subjects' behavior. The number agreement strategies imply error rates significantly bigger than gender agreement strategies. Similar results were observed in Brazilian Portuguese in self-paced reading and auditory experiments (Lourenço-Gomes, 2008). The forced attachment strategy with plural NP2 induced an error rate twice as big as the one of all the other number and gender agreement disambiguation strategies. However, experiments carried out in EP with the same structure manipulating the way of sentence segmentation, including word by word, showed that the interaction between the disambiguation strategy 
through number agreement and the way of the segmentation of the sentences in the self-paced reading technique enforces distinct comprehension effects, especially as to the forced attachments strategy with plural NP2 (Lourenço-Gomes \& Lindemann, 2012). As to the reading times of the critical segment, contrary to what was expected, no significant differences were observed in any of the experiments (but see, Maia et al. 2007 for data from EP and BP; and Soares et al. 2010 for data from EP). The reason for these results is not clear yet, so further investigation is required.

Lourenço-Gomes \& Lindeman (2012) explored interactions between sentence segmentation and number agreement disambiguation in the NP1-P-NP2-RC structure. The authors were focused on methodological aspects of self-paced reading, a technique commonly used in Psycholinguistics. In this technique, sentences are presented to the subjects on a computer screen in a segmented way, and they are instructed to read each segment in the most quick and natural way possible, proceeding this way the complete sentence is read. However, several studies have favoured the notion that the prosodic structure of a text is dealt with as part of the written material input (Fodor, 2002). It can thus be foretold that when a sentence is read silently in its totality, a natural segmentation of the language for that structure is mentally projected onto the stimulus. Therefore, when segmentation is artificially imposed, processing outcomes could be affected (cf. Gilboy \& Sopena, 1996; Lourenço-Gomes, 2008)

Seventy-two graduate students, European Portuguese speakers, participated in the study. The experimental items were modified to undo the ambiguity through number agreement using the complete agreement paradigm between one of the nouns of the complex NP and the RC verb, as in (3 a-d)

(3) a. SPS - SN1 singular-SN2 plural- verb of the relative clause singular

The detective searched for the neighbour of the servants that was involved in several cases.

b. PSP - SN1 singular-SN2 plural- verb of the relative clause singular

The detective searched for the neighbours of the servant that were involved in several cases.

c. SPP - SN1 singular-SN2 plural- verb of the relative clause plural

The detective searched for the neighbour of the servants that were involved in several cases.

d. PSS - SN1 plural SN2 singular - verb of the relative clause plural

The detective searched for the neighbours of the servant that was involved in several cases.

In each of the experiments, a different type of segmentation was used. In the first one, the sentences were segmented and presented in a non-cumulative way, word by word, to avoid that any prosodic contour were mentally projected over the sentence by the subjects. The criteria used in the other two types of segmentation took into account clues from the literature suggesting that a discontinuity between NP2 and the RC would rather favors an attachment to NP1 as in "(...) the neighbour of the servant //that...) than when this discontinuity is absent as in "(...) // the neighbour // of the servants that..." (Jun, 2003, for instance, but see Jun, 2010). The results have showed that (i) the subject's error rate was significantly affected by the disambiguation strategies (3 a-d, above); (ii) in the SPS (3a) and PSS (3d) conditions the segmentation had a significant effect on the subjects's error rate, while in the other two conditions, PSP (3b) and SPP (3c) the effect was just marginal or non-significant. This occurs depending on the types of segmentation employed. Importantly, the interaction between the sentences disambiguation strategy and artificial segmentation employed in self-paced reading can bring about differentiated comprehension effects (see Fonseca, 2012 for others experimental data on prosodic constituents' organization in on-line tasks). 


\section{Conclusion}

In order to provide further insights on/into implicit prosody some points remain to future researches. To name just a few: (i) Given the diversity of information attributed to prosody and considering the time course of processing, it is mandatory to establish what kind of information is at hand, and at what stage. (ii) Different artificial segmentations of the sentence impose differentiated prosodic patterns during reading and, therefore, these patterns can produce differentiated effects on processing. Further studies on forced sentence segmentation are still needed, taking into account its interaction with specific bias in the language studied (for instance, number agreement in Brazilian Portuguese). (iii) It is possible that the subjects' sensitivity to prosodic cues may differ. It might be interesting that in some studies subjects were evaluated in terms of auditory processing skills before or after participating in an experiment. The sensitivity to prosodic cues could also be related to aspects circumscribed to phonological coding during reading and, therefore, some subjects might be more sensitive than others to implicit prosody. (iv) It seems important to establish what acoustical cues in the languages are relevant to sentence processing. And (v) it seems equally important to determine different effects of implicit prosody in different structures. Some structures seem to be more influenced by prosodic aspects than others.

\section{REFERENCES}

1. Augurzky P. Attaching relative clauses in German: The role of implicit and explicit prosody in sentence processing. [PhD]. Universität Leipzig; 2005.

2. Bader M. Prosodic influences on reading syntactically ambiguous sentences. In: Fodor JD, Ferreira, F (Eds.). Reanalysis in sentence processing. Dordrecht: Kluwer Academic, 1998.

3. Baron-Cohen S, Wheelwright S, Skinner R, Martin, J, Clubley. The Autism-Spectrum Quotient (AQ): Evidence from Asperger Syndrome/High-Functioning Autism, Males and Females, Scientists and Mathematicians. Journal of Autism and Developmental Disorders. 2001; 31(1): 5-18.

4. Beach C. The interpretation of prosodic patterns at points of syntactic structure ambiguity: Evidence for cue trading relations. Journal of Memory and Language. 1991; 30: 644-663.

5. Bishop J, Chong A, Jun S. Individual differences in prosodic strategies to sentence parsing. In The Scottish Consortium for ICPhS 2015 (ed.) Proceedings of the 18th International Congress of Phonetic Sciences. Glasgow, UK: the University of Glasgow, 1-5 August 2015. Paper number 0905

6. Buswell GT. The subvocalization factor in the improvement of reading. The Elementary School Journal. 1947; 48(4): 190-196.

7. Carlson K, Clifton Jr. C, Frazier L. Prosodic in adjunct attachment. Journal of Memory and Language. 2001; 45: 58-81.

8. Cuetos F, Mitchell DC. Crosslinguistic differences in parsing: Restrictions on the use of the late closure strategy in Spanish. Cognition. 1988; 30:73-105.

9. Cuetos F, Mitchell DC, Corley MMB. Parsing in different languages. In: Carreiras M; García-Albea JE, Sebastián-Gallés N (eds.) Language processing in Spanish. NJ: Lawrence Erlbaum, 1996.

10. Fernández EM, Sekerina IA. The interplay of visual and prosodic information in the attachment preferences of semantically shallow relative clauses. In: Frazier L, Gibson E (eds.) Explicit and Implicit Prosody in Sentence Processing: Studies in Theoretical Psycholinguistics. NY: Springer. 2015.

11. Finger I, Zimmer MC. Processing short and long relative clauses in Brazilian Portuguese. Trabalho apresentado no GT de Psicolingüística da ANPOLL. Gramado, RS. 2002.

12. Fodor JD. Learning to parse? Journal of Psycholinguistic Research. 1998; 32: 167-195.

13.

Prosodic disambiguation in silent reading. In: Hirotani M (ed.) Proceedings of the North East Linguistic Society 32. 05 April 2002. The City University of New York and New York University, Amherst, Ma: GLSA, 2002a. p. 112-132. 


\section{Lourenço-Gomes}

14. (Ms.) $2002 b$.

Psycholinguistics cannot escape prosody. Graduate Center, City University of New York

15. Fonseca AA. Evidências experimentais da ativação do componente prosódico no input linguístico de sentenças garden-path em Português Brasileiro. Journal of Speech Sciences. 2012; 2(2):65-83.

16. Frazier L, Clifton Jr. C. Construal. MA: MIT Press; 1996

17. Frazier L, Fodor JD. The sausage machine: A new two-stage parsing model. Cognition. 1978; 6: 291325.

18. Frazier L, Gibson E (eds.) Explicit and Implicit Prosody in Sentence Processing: Studies in Theoretical Psycholinguistics. NY: Springer.

19. Frazier L, Rayner K. Making and correcting errors during sentence comprehension: Eye movements in the analysis of structurally ambiguous sentences. Cognitive Psychology. 1982; 14: 178-210.

20 . Resolution of syntactic category ambiguities: Eye movements in parsing lexically ambiguous sentences. Journal of Memory and Language. 1987; 26: 505-526.

21. Frazier L. On comprehending sentences: Syntactic parsing strategies. [PhD]. University of Connecticut; 1979.

22. Frazier L, Clifton Jr. C, Randall J. Filling gaps: Decision principles and structure in sentence comprehension. Cognition. 1983; 13: 187-222.

23. Gibson E, Pearlmutter N, Canseco-Gonzalez E, Hickok G. Recency preference in the human sentence processing mechanism. Cognition. 1996; 59: 23-59.

24. Grillo N, Costa J. A novel argument for the universality of parsing principles. Cognition. 2014; 133: $156-187$

25. 144: $116-122$

Costa J, Fernandes B, Santi A. Highs and lows in English attachment. Cognition. 2015;

26. Hemforth B, Konieczny L, Scheepers C, Strube G. Syntactic ambiguity resolution in German. Syntax and Semantics.1999; 31: 293-309.

27.

Konieczny L. Where pronouns and relative clauses differ: Information structure and binding preferences. Paper presented at the 15th Annual CUNY Conference on Human Sentence Processing, New York, NY. 2002.

28. Hemforth B, Fernández S, Clifton C, Frazier L, Konieczny L, Walter M. Relative clause attachment in German, English, Spanish and French: Effects of position and length. Lingua. 2015; 166: 43-64.

29. Jun Sun-Ah. Prosodic phrasing and attachment preferences. Journal of Psycholinguistic Research. 2003; 32(2): 219-49.

30. Jun Sun-Ah. The implicit prosody hypothesis and overt prosody in English. Language and Cognitive Process. 2010; 25(7/8/9): 1201-1233.

31. Jun S-A, Bishop J. Prominence in relative clause attachment: Evidence from prosodic priming. In: Frazier L, Gibson E (eds.) Explicit and Implicit Prosody in Sentence Processing: Studies in Theoretical Psycholinguistics. NY: Springer. 2015.

32. Kamide Y, Mitchell D, Fodor JD, Inoue A. Relative clause attachment ambiguity: Further evidence from Japanese. Proceedings of the 11th Annual CUNNY Conference, 19-21 March 1998, Rutgers University. New Brunswick: NJ.

33. Lehiste I. Phonetic disambiguation of syntactic ambiguity. Glossa. 7, 1973; 107-122.

34. Signaling of syntactic structure in whispered speech. Folia Linguistica. 1983; 17(1-2): $239-245$

35. Locke JL, Fehr FS. Subvocalization of heard or seen words prior to spoken or written recall. American Journal of Psychology. 1972; 85(1): 63-68.

36. Lourenço-Gomes MC. The length of the relative clause as a factor for testing the IPH in Brazilian Portuguese: A preliminary study. Unpublished Ms. 2002. 
37.

Efeito de comprimento do constituinte na interpretação final de orações relativas estruturalmente ambíguas: um estudo baseado na "Hipótese da Prosódia Implícita". [Mestrado]. Universidade Federal do Rio de Janeiro; 2003.

38. Efeitos de segmentação da sentença sobre o processamento. [Doutorado]. Universidade Federal do Rio de Janeiro; 2008.

39.

Maia M, Moraes JA. Prosódia implícita na leitura silenciosa: um estudo com orações relativas estruturalmente ambíguas. In: Maia M Finger I (eds.). Processamento da Linguagem. Pelotas: Educat; 2005. p. 131-62.

40 .

, Maia M. Efeitos do status argumental e de segmentação no processamento de sintagmas preposicionais em português brasileiro. In: V Congresso Internacional da Associação Brasileira de Lingüística, 28.02 - 03.03.2007. Universidade Federal de Minas Gerais. Belo Horizonte: UFMG; 2006.

41. Lindemann V. Interações entre estratégias de segmentação e modo de segmentação de sentenças em self-paced reading. Textos Selecionados do XXVII Enconto Nacional da Associação Portuguesa de Linguística. Lisboa: APL; 2012.

43. Magalhães JO, Fonseca A. A Prosódia de sentenças com atributos ambíguos. (Con)Textos Linguísticos. 2014; 8(10.1): 72-86.

44.

Maia M. Implicit prosody effects on the attachment of attributes to NPs in Brazilian Portuguese. Proceedings of the 19th Annual CUNY Conference. 23-25 March 2006. New York, NY. 2006.

45 . Maia M. Pistas prosódicas implícitas na resolução de ambiguidades sintáticas: um caso de adjunção de atributos. Revista da ABRALIN. 2006; 5(1/2): 143-167.

46. Maia M, Costa A, Fernández, E Lourenço-Gomes MC. A compreensão de orações relativas em português brasileiro e europeu: um estudo comparativo. Revista da ABRALIN. 2004; 3(1/2): 11-40.

47. Fernández E, Costa A, Lourenço-Gomes MC. Early and late preferences in relative clause attachment in Brazilian and European Portuguese. Journal of Portuguese Linguistics. 2007; 6 (1): 227 250 .

48. , Finger. Referencialidade e domínio temático na compreensão de orações relativas curtas e longas em português. Linguística. 2007; 3(2): 249-278.

49. Mitchell DC, Cuetos F. The origins of parsing strategies. In: Smith, C (Ed.) Current issues in natural language processing. Austin, TX: University of Austin; 1991.

50. Nespor M, Vogel I. Prosodic Phonology. Dordrecht-Holland: Foris Publications. 1986.

51. Price PJ, Ostendorf S, Shattuck-Hufnagel S, Fong C. The use of prosody in syntactic disambiguation. JASA. 1991; 90: 2956-2970.

52. Pynte J, Colonna S. Decoupling syntactic parsing from visual inspection: The case of relative clause attachment in French. In: Kennedy A, Radach R, Heller D, Pynte J (Eds.). Reading as a Perceptual Process. Oxford, UK: Elsevier; 2000.

53. Quinn D, Fernández E, Almeida R G, Bradley D, Fodor JD. Prosodic phrasing predicts RC attachment in French and English silent reading. Proceedings of AMLaP Conference. Saarbrücken, September, 2001.

54. Sandalo F, Truckenbrodt H. Some notes on phonological phrasing in Brazilian Portuguese. MIT Working Papers in Linguistics. 2002;42: 285-310.

55. Schafer A. Prosodic Parsing: The role of prosody in sentence comprehension. [PhD]. University of Massachusetts Amherst; 1997.

56. Shattuck-Hufnagel S, Turk AE. A prosody tutorial for investigators of auditory sentence processing. Journal of Psycholinguistic Research. 1996; 25:193-247.

57. Slowiaczek ML, Clifton Jr C. Subvocalization and reading for meaning. Journal of Verbal Learning and Verbal Behavior. 1980; 19:573-582.

58. Standing L, Curtis L. Subvocalization rate versus other predictors of the memory span. Psychological Reports. 1989; 65:487-495. 
59. Standing L, Bond B, Smith P, Isely C. Is the immediate memory span determined by subvocalization rate? British Journal of Psychology. 1980; 71: 525-539.

60. Streeter L. Acoustic determinants of phrase boundary perception. JASA. 1978; 64(6):1582-1592.

61. Traxler M. Working memory contributions to relative clause attachment processing: A hierarchical linear modeling analysis. Memory and Cognition. 2007; 35:1107-1121.

62. Traxler, Matthew. A hierarchical linear modeling analysis of working memory and implicit prosody in the resolution of adjunct attachment ambiguity. Journal of Psycholinguistic Research. 2009; 38:491-509.

63. Umeda N. Boundary: Perceptual and acoustic properties and syntactic and statistical determinants. Speech and Language. 1982; 7: 333-371.

64. Wijnen F. Dutch relative clauses in two- and three-sites contexts. Proceedings of the 11th Annual CUNNY Conference, 19-21 March 1998, Rutgers University. New Brunswick: NJ. 1998. 